Amann, K. 462

Cross, J. 459

Descamps-Latscha, B. 481

Drüeke, T.B. 494

Esch, S. van 489

Floege, J. 473

Fujiwara, N. 466

Girndt, M. 485

Ho-dac-Pannekeet, M.M. 489

Jahnen-Dechent, W. 473

Jungers, P. 481

Ketteler, M. 473

Krane, V. 451

Krediet, R.T. 489
Lindholm, B. 454

Lonnemann, G. 444

Massy, Z.A. 494

Michels, W.M. 489

Nakamura, M. 466

Nascimento, M.M. 454

Okumura, K. 466

Osanai, T. 466

Osawa, H. 466

Pecoits-Filho, R. 454

Ratcliffe, P.J. 445

Riella, M.C. 454

Saitoh, M. 466

Sasaki, S. 466
Smit, W. 489

Stenvinkel, P. 454

Struijk, D.G. 489

Tomita, H. 466

Tyralla, K. 462

Van Biesen, W. 477

Vanholder, R. 477

Vermeer, C. 473

Wanner, C. 451, 473

Westenfeld, R. 473

Witko-Sarsat, V. 481

Yamabe, H. 466

Zoccali, C. 469

Zweers, M.M. 489

\title{
Subject Index Proceedings
}

Advanced oxidation protein products 481 494

Asymmetric dimethylarginine 469

- dimethyl- $L$-arginine 466

Atheroma 459

Atherosclerosis 454, 469, 485

Bacteremia 477

Capillaries 462

Cardiovascular risk 469

Chronic inflammation 485

- kidney failure 485

- renal failure 481

C-reactive protein 485

- - hemodialysis 473

Cholesterol 451

Cytokines 485

Developing countries 454

Dialysis 469

-, morbidity and mortality 477
Dyslipidemia 451

Endothelial function 459

End-stage renal disease 466, 469

Erythropoietin 445

Fetuin 473

Fibrosis 462

Free radicals 459

Hemodialysis 481

Hepatitis 477

Hydroxylase 445

Hypertension 466, 469

Hypoxia-inducible factor 445

Immune dysregulation 481

Infections, preventive measures 477

Inflammation 454, 473, 481

Kidney failure, chronic 485

Left ventricular hypertrophy 462

Lipoprotein 451

Malnutrition 454
Matrix Gla protein 473

Microarteriopathy 462

Metabolism 485

Nitric oxide 459, 466

Oxidation 451

Oxidative stress 481,494

Oxygen sensing 445

Parathyroid hormone 494

Pathogenetic mechanisms 489

Peritoneal dialysis, continuous ambulatory 489

Prolyl hydroxylase 445

Renal failure 459, 462

Salt 466

Ultrafiltration failure 489

Uremia 451, 469, 494

Vascular calcification 473,494

Viral infections 477

\section{KARGER}

(C) 2002 S. Karger AG, Basel

Fax + 41613061234

E-Mail karger@karger.ch

www.karger.com
Accessible online at

www. karger.com/journals/bpu 